\title{
Characterization of dendritic cells and follicular dendritic cells in the hepatic lymph nodes and liver of sheep experimentally infected with Fasciola hepatica
}

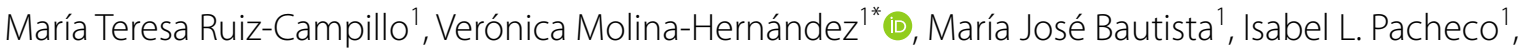 \\ Rafael Zafra ${ }^{2}$, Leandro Buffoni², Francisco Javier Martínez-Moreno², Alvaro Martínez-Moreno² and José Pérez ${ }^{1}$
}

\begin{abstract}
Fasciola hepatica has been shown to have a high capacity for immunomodulation of the host response, making the development of protective vaccines extremely difficult. One of these immunomodulation mechanisms is the impairment of dendritic cells (DC) maturation and, therefore, suppression of antigenic presentation. The aim of this study was to evaluate the pathological changes as well as the characterization of two antigen presenting cells, DC (CD1b, CD83 and MHC-II positive) and follicular dendritic cells (FDC) (CNA.42, S100 and CD83 positive) by immunohistochemistry in the hepatic lymph nodes (HLN) and livers of sheep during the early stages of infection with F. hepatica [9 and 18 days post-infection (dpi)], compared with an uninfected group (UC) as a control. The results revealed a marked hyperplasia of HLN germinal centres at 9 and, in particular, $18 \mathrm{dpi}$, with respect to the UC group, with coincidental increased expression of CNA.42 in FDC of lymphoid follicles and CD1b in the DC of paracortical areas at 18 dpi. However, the expression of MHC-II and CD83 decreased at 9 and, particularly, at 18 dpi in HLN compared with that in the UC group. Since both markers are related to active presentation of antigens by DC and FDC, the results of the present study suggest that, despite the marked hyperplasia of HLN and increase in DC and FDC numbers during early stages of infection, the DC and FDC antigenic presentation capacity, as suggested by the expression of the markers MHC-II and CD83, is suppressed by the parasite. This suppression was not observed in the liver, probably because of the low number of DC. This is the first study of the immunophenotype of DCs and FDC in sheep infected with F. hepatica.
\end{abstract}

\section{Introduction}

Fasciolosis, caused by F. hepatica, results in major economic losses to the agricultural sector [1]. The parasite infects a wide range of domestic animals, including cattle, sheep and goats, and the disease has been recognized as an important zoonosis in Africa, Asia, Europe, America and Oceania [2,3]. Control of the disease has

\footnotetext{
*Correspondence: b62mohev@uco.es

1 Department of Anatomy and Comparative Pathology, Faculty

of Veterinary Medicine, University of Córdoba, Sanidad Animal Building, Rabanales Campus, Córdoba, Spain

Full list of author information is available at the end of the article
}

traditionally been based on the use of anthelmintic drugs such as triclabendazole. Nevertheless, resistance to this and other drugs, together with public concern about the presence of drug metabolites in foodstuff, is increasing in numerous countries [4]. Because of this, there is increasing interest in the development of an immunological method of control for the disease [5, 6]. Despite major efforts during the last two decades, the search for an effective vaccine to control fasciolosis has been slow due to the different mechanisms used by $F$. hepatica to modulate the host immune response, which have rendered attempted therapies ineffective in killing the parasite [7-9]. One of these mechanisms is the impairment 
of the maturation of dendritic cells (DC), which facilitate both parasite survival and modulation of the immune response [10-12].

DC are specialized antigen-presenting cells that can be found in the paracortical area of the lymph nodes where they promote the activation of naive $\mathrm{T}$ lymphocytes. On the other hand, follicular dendritic cells (FDC) are cells of stromal origin located in the central region of primary follicles and in the light zone of germinal centres of secondary and tertiary lymphoid organs. They play a crucial role in B-cell activation and have the unique capacity to bind and retain native antigen in B-cell follicles for long periods of time [13, 14]. In previous papers, it has been reported that $F$. hepatica is able to downregulate the Th1 immune response and upregulate the Th2 response at early stages of infection in sheep [15] and mice [16], as well as in chronic stages in cattle [17]. This imbalance towards a Th2 immune profile is mediated through regulatory cytokines and cells, such as DC, that modulate and/or suppress inflammatory responses. It has been determined that different antigenic preparations of this parasite, such as total extract, $F$. hepatica tegumental antigen (FhTeg) and excretory-secretory products (ESPs), decrease the activation state of DC in mice $[11,12,18$, 19], and F. gigantica ESPs induce the modulation of buffalo DC [20]. More specifically, it has been reported that FhTeg induces DC modulation, resulting in a lack of $\mathrm{T}$ cell Th1 cytokine response and proliferation [21]. In addition, the glycan products produced by $F$. hepatica participate in the modulation of DC maturation and mediate the production of IL-10 and IL-4 during infection, inducing a Th2/regulatory-polarized immune response [22-25]. F. hepatica can also induce the development of phenotypes that are characterized by a decreased production of proinflammatory cytokines, as well as the expression of general markers that are characteristic of an M2 macrophage phenotype and have been shown to promote the differentiation of Th2 and Treg cells [26-28]. Moreover, it has been reported that F. hepatica cathepsin L1 (FhCL1), glutathione transferase (FhGST) and Kunitz-type molecule induce a modulatory effect on DC, which leads to the suppression of the adaptive immune response, including Th1- and/or Th17-related responses [10, 29]. To date, the effect of $F$. hepatica infection on FDC has not been evaluated.

On the other hand, it has been shown that recombinant forms of FhCL1 and FhGST can partially activate DC [10]. Moreover, a mucin-like peptide from $F$. hepatica (Fhmuc) induces parasite-specific adaptive immunity with increased levels of IFN- $\gamma$ and specific IgG antibodies [30]. In a recent study, it was also reported that the interactions of DC with F. hepatica cathepsin L3 (FhCL3) confer a unique expression pattern of the cytokines IFN- $\gamma$ and IL-13, which may be protective in this parasitosis or in other helminth infections [31].

Most studies investigating the modulation of DC by $F$. hepatica have been carried out in murine models, with only one study in buffaloes [20]. Therefore, to date, there is little available information on $F$. hepatica-induced modulation of DC in ruminants. The aim of the present study was to evaluate the expression of different markers of DC (CD1b, CD83 and MHC-II) and of FDC (CNA.42, S100 and CD83) in the HLNs and liver of sheep during the early stages of infection with $F$. hepatica. These markers have been selected because they have been used as markers of DC, FDC and antigen-presenting cells in formalin-fixed peripheral lymph nodes in sheep [13, 32]. This is the first study to evaluate the immunophenotype of DC and FDC present within the HLNs and livers of sheep experimentally infected with $F$. hepatica in the early stages of infection.

\section{Materials and methods \\ Experimental design}

Fifteen eight-month-old male Merino-breed sheep obtained from a liver fluke-free farm were used for this study. All animals were tested monthly for parasite eggs by faecal sedimentation, with negative results in all cases. Moreover, prior to challenge, all animals were tested for serum IgG specific for FhCL1 by an enzyme-linked immunosorbent assay (ELISA), with negative results in all cases. Animals were housed indoors $\left(100 \mathrm{~m}^{2}\right.$ covered and $100 \mathrm{~m}^{2}$ uncovered facility) and fed with hay and pellets and given water ad libitum. The study consisted of three groups with five sheep each $(n=5)$, including two infected groups and an uninfected control (UC) group. Sheep were orally infected with one dose of 150 metacercariae of the Italian strain of $F$. hepatica (Ridgeway Research Ltd, UK), and all animals were euthanised in batches of five according to the groups at 9 and 18 days post-infection (dpi), being the UC group euthanised at the end of the trial. Sheep did not receive vaccines or adjuvants. In all animals, euthanasia was conducted by intravenous injection of $7 \mathrm{~mL}$ of embutramide $(200 \mathrm{mg}$ ) and mebezonium iodide $(50 \mathrm{mg})$. No adverse reactions or clinical signs were noted during the experiments. The experiment was approved by the Bioethics Committee of the University of Cordoba (code No. 1118) and conducted in accordance with European (2010/63/UE) and Spanish (RD 1201/2005) directives on animal experimentation.

\section{Histopathology}

At necropsy, the liver was removed, and the visceral and diaphragmatic aspects were photographed for gross evaluation. Liver and HLN tissue samples were collected and fixed in $10 \%$ neutral buffered formalin for $24 \mathrm{~h}$, then 
routinely processed and embedded in paraffin wax. Tissue sections $(4 \mu \mathrm{m}$ thick) were stained with haematoxylin and eosin (H\&E) for histopathology.

\section{Immunohistochemical analysis}

An immunohistochemical study was used to assess CNA.42, CD1b, S100, MHC-II and CD83 expression in HLN and liver tissue samples using the avidin-biotinperoxidase method, as described elsewhere [33]. Briefly, after hydration of samples, antigen retrieval was carried out using different methods depending on the antibody. The anti-CNA.42 treatment consisted of incubating the slides with citric acid ( $\mathrm{pH} 9$ ), followed by heating in a microwave for $20 \mathrm{~min}$. anti-MHC-II was incubated with

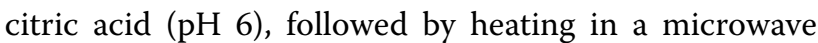
for $10 \mathrm{~min}$. anti-CD83 and anti-CD1b were subjected to pronase digestion, and anti-S100 did not require any specific treatment. The samples were rinsed twice for $5 \mathrm{~min}$ in phosphate-buffered saline (PBS) and $5 \mathrm{~min}$ in PBS-Tween 80 (Panreac, Barcelona, Spain). Endogenous peroxidase activity was blocked by incubation with $3 \%$ hydrogen peroxide (Panreac, Barcelona, Spain) in methanol (Panreac, Barcelona, Spain). The slides were then rinsed twice for $10 \mathrm{~min}$ in PBS and incubated with $25 \%$ normal goat serum (Vector Laboratories, Burlingame, California, USA) for $30 \mathrm{~min}$ at room temperature. Each primary antibody was diluted 1:100 in PBS containing $10 \%$ normal goat serum, applied to the slides and incubated overnight at $4{ }^{\circ} \mathrm{C}$. The primary antibody details are shown in Table 1 . We then rinsed the slides three times in PBS prior to the addition of secondary antibody. Biotinylated goat anti-rabbit immunoglobulin serum (Dako-Agilent, Santa Clara, California, USA), was diluted 1:200 and applied to the slides incubated with the primary polyclonal S100 antibody, whereas biotinylated goat anti-mouse immunoglobulin serum (Dako-Agilent, Santa Clara, California, USA), diluted 1:50, was used for the slides incubated with the primary monoclonal CNA.42, MHC-II, CD83 and CD1b antibodies. Slides with secondary antibodies were incubated for $30 \mathrm{~min}$ at room temperature. After three rinses for $10 \mathrm{~min}$ in PBS, an avidin-biotin-peroxidase complex (Vector Laboratories, Burlingame, California, USA) diluted 1:50 in PBS was applied for $1 \mathrm{~h}$ at room temperature in darkness. The tissue sections were washed three times in Tris-buffered saline (pH 7.2) and incubated with the vector NovaRED ${ }^{\circledR}$ peroxidase substrate (Vector Laboratories, Burlingame, California, USA) for $2 \mathrm{~min}$. Then, samples were rinsed in tap water, lightly counterstained with Mayer's haematoxylin and mounted with Eukitt ${ }^{\circledR}$ (Freiburg, Germany). Specific primary antibodies were substituted with PBS or non-immune isotype-matched sera as negative controls. HLN sections from sheep were used as positive controls.

\section{Morphology and cell counting}

A morphological analysis was carried out to evaluate the size of CNA.42+ germinal centres in infected and control animals. The length of the major and minor radii of five random follicular germinal centres was measured, and the area (expressed in $\mu \mathrm{m}^{2}$ ) was calculated as follows: $\pi \times a \times b$, where a was the minor radius, and $b$ was the major radius (Figure 1). Ten random microphotographs of $0.08 \mathrm{~mm}^{2}$ were taken, and five follicular germinal centres per animal were measured and multiplied to obtain the area expressed in $\mu \mathrm{m}^{2}$. This calculation, together with the cell count of CNA.42+, CD1b+, S100+, MHC-II+ and CD83+ cells in the HLN and liver tissue sections, was performed using the biomedical software Image v.1.51d. One lymph node and one liver slide per animal were used, five random microphotographs at $\times 400$ magnification were taken from each slide, and the number of positive cells was counted. Specifically, CNA.42+ cells were counted inside lymph node follicular germinal centres (Figure 2); MHC-II+ (Figure 4), CD83+ (Figure 5) and $\mathrm{S} 100+$ cells were counted in the follicles, paracortical and medullary areas; and CD1b was counted in the paracortical and medullary areas (Figure 3). The results are expressed as the mean $\pm \mathrm{SD}$ per group.

Table 1 Specifications of the primary antibodies used for immunohistochemistry

\begin{tabular}{|c|c|c|c|c|}
\hline Specificity & Type & Clone/product code & Dilution & Source \\
\hline FDC & Mouse anti-human mAba & CNA.42/M7157 & $1: 10$ & Dako \\
\hline$M H C-I I$ & Mouse anti-human mAb & HI2A/M0748 & $1: 100$ & VMRD \\
\hline CD83 & Mouse anti-human mAba & HB15e/MCA1582GA & $1: 50$ & BioRad \\
\hline CD1b & Mouse anti-bovine $\mathrm{mAb}^{c}$ & CC20/MCA2058G & $1: 10$ & BioRad \\
\hline $\mathrm{S} 100$ & Rabbit pAba & $-/ Z 0311$ & $1: 200$ & Dako \\
\hline
\end{tabular}

mAb: monoclonal antibody, pAb: polyclonal antibody.

a Antibody with cross-reactivity proved in sheep [13].

b Antibody with cross-reactivity proved in sheep [66]

c Antibody with cross-reactivity proved in sheep (manufacturer data sheet). 


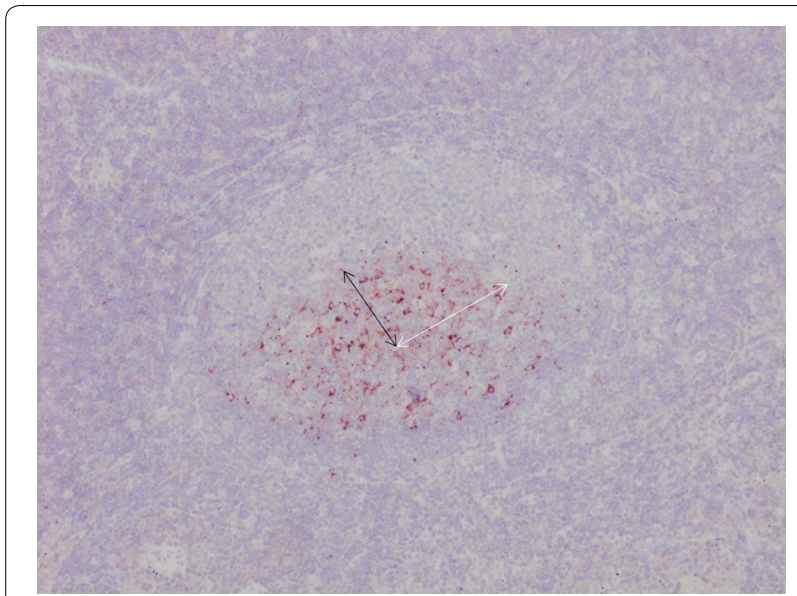

Figure 1 CNA.42+ cells in a germinal centre inside a lymph node follicle from a sheep $\mathbf{1 8} \mathbf{d p i}$. The major radius (white arrow) and the minor radius (black arrow) are marked. ABC-haematoxylin counterstain, $\times 100$.

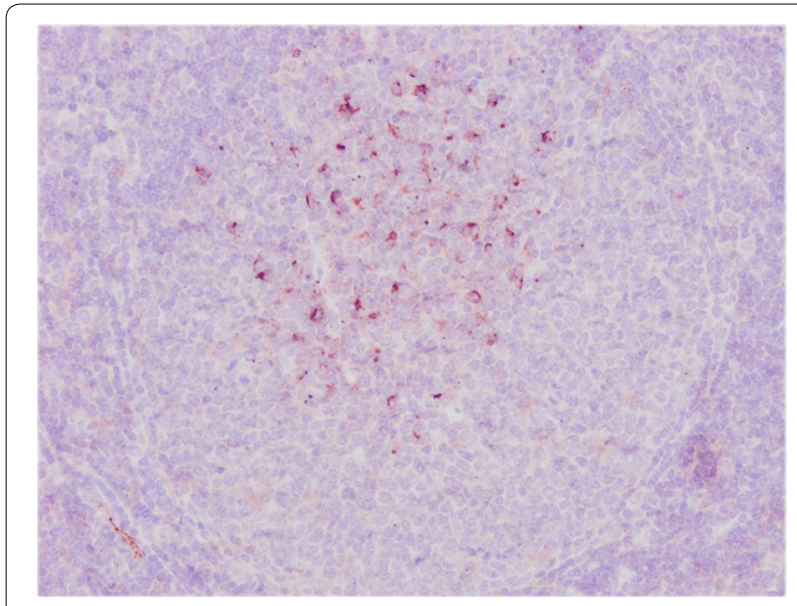

Figure 2 CNA.42+ cells in a germinal centre in follicles of a lymph node from a sheep $18 \mathrm{dpi}$. ABC-haematoxylin counterstain, $\times 200$.

\section{Statistical analysis}

Statistical analysis was carried out using the GraphPad Prism 7.0 software package (GraphPad Software, Inc., San Diego, USA). The Kolmogorov-Smirnov test was applied to evaluate whether distributions were parametric. Comparisons between groups were made using the Mann-Whitney test for non-parametric distributions. Correlation studies were carried out using the Spearman correlation test for nonparametric distributions. $P<0.05$ was considered significant.

\section{Results}

\section{Histopathology}

Livers from the UC group showed no histopathological changes. Portal spaces showed occasional lymphocytes, and eosinophils were not found in the negative control livers. All animals at 9 dpi presented necrotic foci and focal haemorrhages, mainly involving the subcapsular areas. Necrotic foci showed abundant cell debris and a mild to moderate infiltrate of eosinophils, often with pyknotic nuclei. Necrotic tracts started $0.5-1.5 \mathrm{~mm}$ behind migrating larvae. Animals at 18 dpi presented microscopic lesions characterized by the presence of necrotic foci and tortuous pathways located in the hepatic parenchyma, mainly in the subcapsular areas. Associated with the foci and necrotic paths, we found a variable inflammatory infiltrate composed mainly of eosinophils, macrophages and occasional neutrophils, together with cellular debris and peripheral haemorrhages. The portal spaces adjacent to the necrotic foci showed a severe inflammatory infiltrate, composed mainly of lymphocytes, macrophages and eosinophils. These findings suggest that the pathway of entry of inflammatory cells into the hepatic parenchyma is through the portal veins. At $18 \mathrm{dpi}$, granulomas were also found, and they were composed of a necrotic centre surrounded peripherally by macrophages arranged in palisade and lymphocytes and eosinophils.

The HLNs of the UC group showed a small cortex with primary lymphoid follicles or secondary lymphoid follicles with small germinal centres. Paracortical areas and medullary cords were also small and composed of lymphocytes, macrophages and occasional plasma cells. Eosinophils were not found. The area of germinal centres was $23953 \pm 5380 \mu \mathrm{m}^{2}$ in the UC group and $47585 \pm 4321 \mu^{2}$ at $9 \mathrm{dpi}$ and $61631 \pm 4743 \mu \mathrm{m}^{2}$ at $18 \mathrm{dpi}$ in the infected groups. Significant differences were found between the UC group and the infected group 9 and $18 \mathrm{dpi}(P<0.01$ and $P<0.001$, respectively). The medullary cords also showed hyperplasia at 9 and 18 dpi due to increased numbers of lymphocytes, plasma cells and macrophages. Infiltration of eosinophils was variable in the paracortical area and medulla of infected animals, in which hemosiderin pigment was found in the cytoplasm of a variable number of medullary macrophages.

\section{Immunohistochemistry}

The anti-CNA.42 mAb yielded cytoplasmic immunostaining in FDC, mainly located in germinal centres of the secondary lymphoid follicles of HLNs (Figures 1 and 2). Only FDC located in the lymphoid follicles were counted. The results of the immunohistochemical study of CNA.42+ cells are summarized in Table 2 . The 

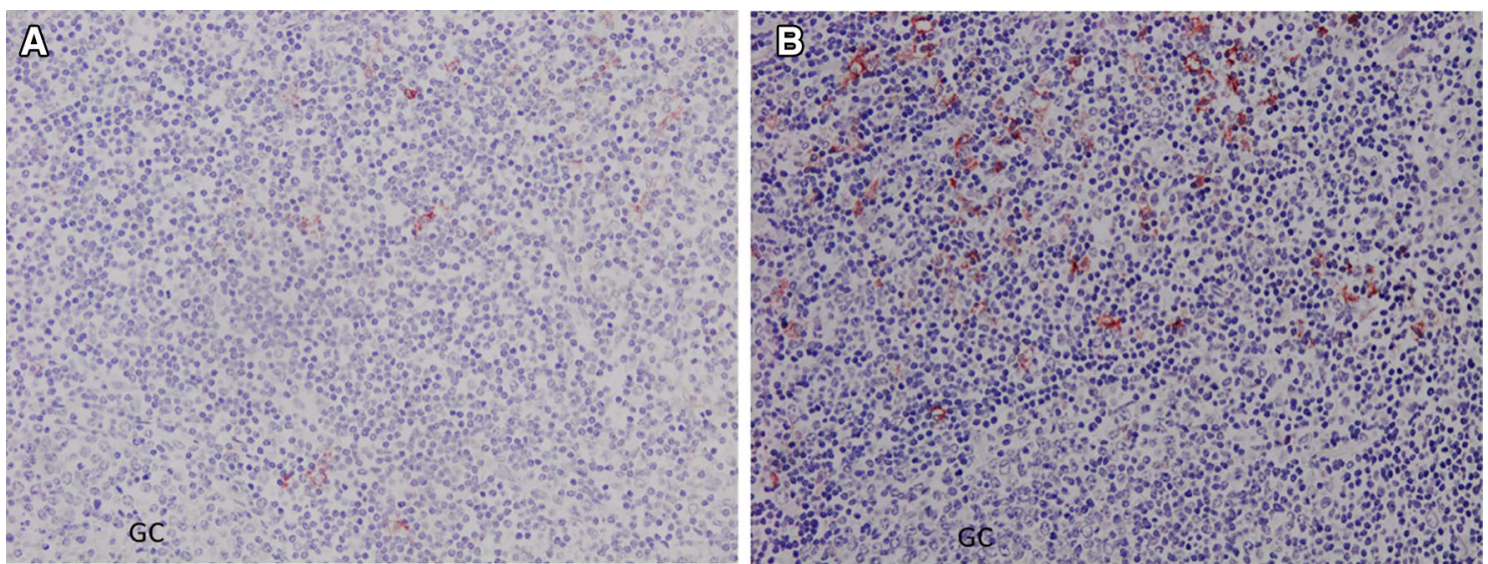

Figure $3 \mathrm{CD} 1 \mathrm{~b}+$ cells in the paracortical area of a lymph node. A. From an uninfected control sheep. B. From a sheep $18 \mathrm{dpi}$. GC: germinal centre. ABC-haematoxylin counterstain, $\times 200$

Table 2 Number of CD1b+, S100+, MHC-II+ and CD83+ cells in HLNs (medullary, paracortical and follicular areas) and livers expressed as the mean $\pm S D$ per area of $0.08 \mathrm{~mm}^{2}$ per animal

\begin{tabular}{|c|c|c|c|c|c|}
\hline Antibody & Group & Medullary area HLNs & Paracortical area HLNs & Follicular area HLNs & Livers \\
\hline \multirow[t]{3}{*}{ CNA.42 } & UC & - & - & $43.1 \pm 11$ & - \\
\hline & $9 \mathrm{dpi}$ & - & - & $71.6 \pm 6.3$ & $6.5 \pm 10.8$ \\
\hline & $18 \mathrm{dpi}$ & - & - & $93.2^{\complement} \pm 10.1$ & $6.8 \pm 10.1$ \\
\hline \multirow[t]{3}{*}{ CD1b } & UC & $6.2 \pm 0.8$ & & - & - \\
\hline & $9 \mathrm{dpi}$ & $12.7 \pm 2.2$ & & - & $2.1 \pm 3.4$ \\
\hline & $18 \mathrm{dpi}$ & $19.6^{c} \pm 4.6$ & & - & $5.7^{b} \pm 3.6$ \\
\hline \multirow[t]{3}{*}{ S100 } & UC & $8.7 \pm 2.6$ & $9.0 \pm 6.9$ & $14.9 \pm 10.1$ & $1 \pm 0.1$ \\
\hline & $9 \mathrm{dpi}$ & $4.7 \pm 0.9$ & $5.8 \pm 2.0$ & $6.8 \pm 4.3$ & $2.3 \pm 1.5$ \\
\hline & $18 \mathrm{dpi}$ & $12.6^{b} \pm 1.5$ & $16.3^{\mathrm{a}} \pm 4.6$ & $21.8^{\mathrm{a}} \pm 7.1$ & $3.9^{b} \pm 2.5$ \\
\hline \multirow[t]{3}{*}{ MHC-II } & UC & $19.8 \pm 1.7$ & $34.2 \pm 1.5$ & $16.1 \pm 1.7$ & $11.8 \pm 9$ \\
\hline & $9 \mathrm{dpi}$ & $13.4^{\mathrm{a}} \pm 3.1$ & $16.2^{\mathrm{a}} \pm 3.8$ & $1.6^{\mathrm{d}} \pm 0.8$ & $23.6^{\mathrm{b}} \pm 5.5$ \\
\hline & $18 \mathrm{dpi}$ & $1.9^{\mathrm{d}} \pm 0.6$ & $7.7^{d} \pm 4.2$ & $0.2^{\mathrm{b}} \pm 0.7$ & $34^{d} \pm 9$ \\
\hline \multirow[t]{3}{*}{ CD83 } & UC & $26.8 \pm 6.4$ & $53.1 \pm 13.6$ & $84 \pm 10.4$ & $0.6 \pm 0.6$ \\
\hline & $9 \mathrm{dpi}$ & $67.4^{b} \pm 10.7$ & $27^{\mathrm{a}} \pm 5.4$ & $29.7^{\mathrm{a}} \pm 9.4$ & $2 \pm 2.9$ \\
\hline & $18 \mathrm{dpi}$ & $75^{\mathrm{b}} \pm 9.8$ & $34.5 \pm 1.4$ & $18.9^{\mathrm{a}} \pm 2$ & $4.9^{c} \pm 2.5$ \\
\hline
\end{tabular}

CNA.42 is expressed as the number of positive cells per germinal centre. Statistical differences are in comparison with the UC group. UC: uninfected control group, dpi: days post-infection.

a $(P<0.05),{ }^{b}(P<0.01),{ }^{c}(P<0.001),{ }^{d}(P<0.0001)$.

number of CNA.42+ FDC in the germinal centres of the HLN follicles in animals at 18 dpi increased significantly $(P<0.001)$ in comparison with the that in the UC group. In the liver, CNA.42+ cells showed stellate shape and they were observed in the inflammatory infiltrates composed of numerous lymphoid cells arranged in lymphoid follicles surrounding portal spaces and in the periphery of granulomas. The number of CNA.42+ FDC in the liver increased significantly at $9 \mathrm{dpi}(P<0.05)$ and $18 \mathrm{dpi}$ $(P<0.01)$ compared to that in the UC group (Table 2$)$.
However, high individual variability was observed in the liver for CNA.42, in part due to the variability in the extent of the inflammatory infiltrates arranged in lymphoid follicles. CNA. $42+$ cells were not found in the UC group.

The anti-CD1b mAb yielded cytoplasmic immunostaining in DC located in paracortical and medullary areas of HLNs (Figure 3). The results of the immunohistochemical study of CD1b are summarized in Table 2. The number of CD1b+ DC in HLNs at 18 dpi increased 
significantly $(P<0.0001)$ compared to that in the UC group. In the liver, $\mathrm{CD} 1 \mathrm{~b}+$ cells were observed in the inflammatory infiltrates surrounding portal spaces and in the periphery of granulomas. The number of CD1b+ DC in the liver increased significantly at $18 \mathrm{dpi}(P<0.01)$ compared with that in the UC group (Table 2).

The anti-S100 pAb yielded nuclear and/or cytoplasmic immunostaining in peripheral nerves (internal positive control). In addition, only stromal stellate cells located in lymphoid follicles, paracortical areas and medullary cords of HLNs were considered for the cell count. The results of the immunohistochemical study of S100 are summarized in Table 2. The number of S100+ stromal cells in lymphoid follicles and in paracortical and medullary areas in HLNs showed no significant differences between infected animals (9 and $18 \mathrm{dpi}$ ) and uninfected controls. In the liver, S100+ cells were observed in inflammatory infiltrates surrounding portal spaces and in the periphery of granulomas. The number of $\mathrm{S} 100+$ stromal cells in the liver increased significantly at $18 \mathrm{dpi}(P<0.01)$ in comparison with the number in the UC group.

The anti-MHC-II mAb yielded cytoplasmic immunostaining of stellate cells located in follicles, paracortical areas and medullary areas of HLNs (Figure 4). A variable number of lymphocytes showed a positive MHC-II immunoreactivity; however, only cells with large cytoplasm and cytoplasmic prolongations, an appearance compatible with DC, were considered for the cell count. The results of the immunohistochemical study of MHCII are summarized in Table 2. The number of MHC-II+ cells decreased significantly in HLN lymphoid follicles, paracortical and medullary areas at 9 and $18 \mathrm{dpi}$ compared to that in the UC group. In the liver, MHC-II+ cells were found in the inflammatory infiltrates of portal spaces and in the periphery of granulomas. The number of MHC-II+ cells in the liver increased significantly at $9 \mathrm{dpi}(P<0.01)$ and at $18 \mathrm{dpi}(P<0.0001)$ in comparison with that in the UC group (Table 2).

The anti-CD83 mAb yielded cytoplasmic immunostaining in stellate cells located in lymphoid follicles, paracortical areas and medullary cords of HLNs (Figure 5). The results of the immunohistochemical study of CD83 are summarized in Table 2. The number of CD83+ FDC decreased significantly in lymphoid follicles at $9 \mathrm{dpi}$ $(P<0.05)$ and at $18 \mathrm{dpi}(P<0.05)$, as well as the number of CD83+ DC in the paracortical areas at $9 \mathrm{dpi}(P<0.05)$ and mononuclear cells in the medulla at $9 \mathrm{dpi}(P<0.01)$ and at $18 \mathrm{dpi}(P<0.01)$, in comparison with the respective numbers in the UC group. In the liver, CD83+ mononuclear cells were found in the inflammatory infiltrates of portal spaces and in the periphery of granulomas. Since the livers of the UC group showed only occasional inflammatory cells (lymphocytes, macrophages and stellate cells) in the portal areas, the number of CD83+ cells was quite low. In the infected groups, the number of CD83+ cells in the liver increased significantly at $18 \mathrm{dpi}$ $(P<0.001)$ in comparison with that in the UC group (Table 2).

\section{Discussion}

The gross pathology and microscopic changes (acute necrotic foci and tracts behind migrating larvae) found in the liver at 9 and $18 \mathrm{dpi}$ are in accordance with the gross lesions reported during early stages of infection in sheep [34, 35] and goats [36, 37]. The marked hyperplasia of HLN lymphoid follicles and medullary cords found at 9 and, particularly, at 18 dpi suggests a strong local humoral immune response, as reported previously in sheep with chronic fasciolosis [34, 38-40].
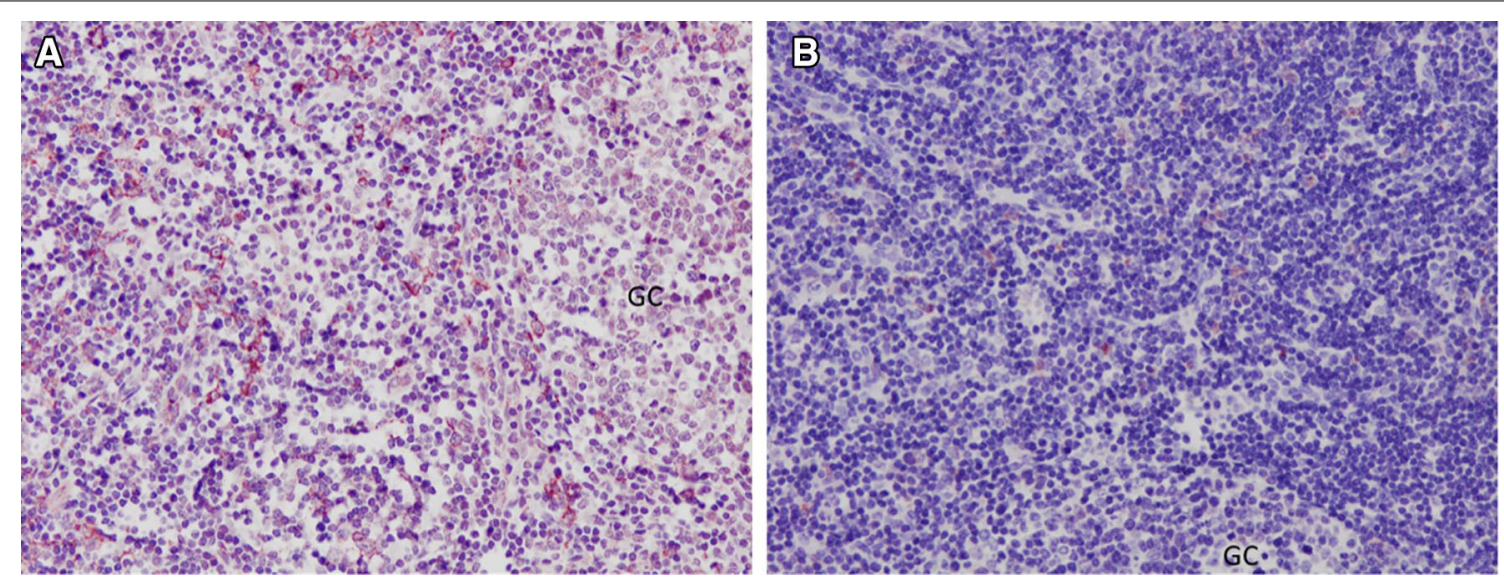

Figure 4 MHC-II+ cells in the follicular and paracortical area of a lymph node. A. From an uninfected control sheep. B. From a sheep $18 \mathrm{dpi}$. GC: germinal centre. ABC-haematoxylin counterstain, $\times 200$. 

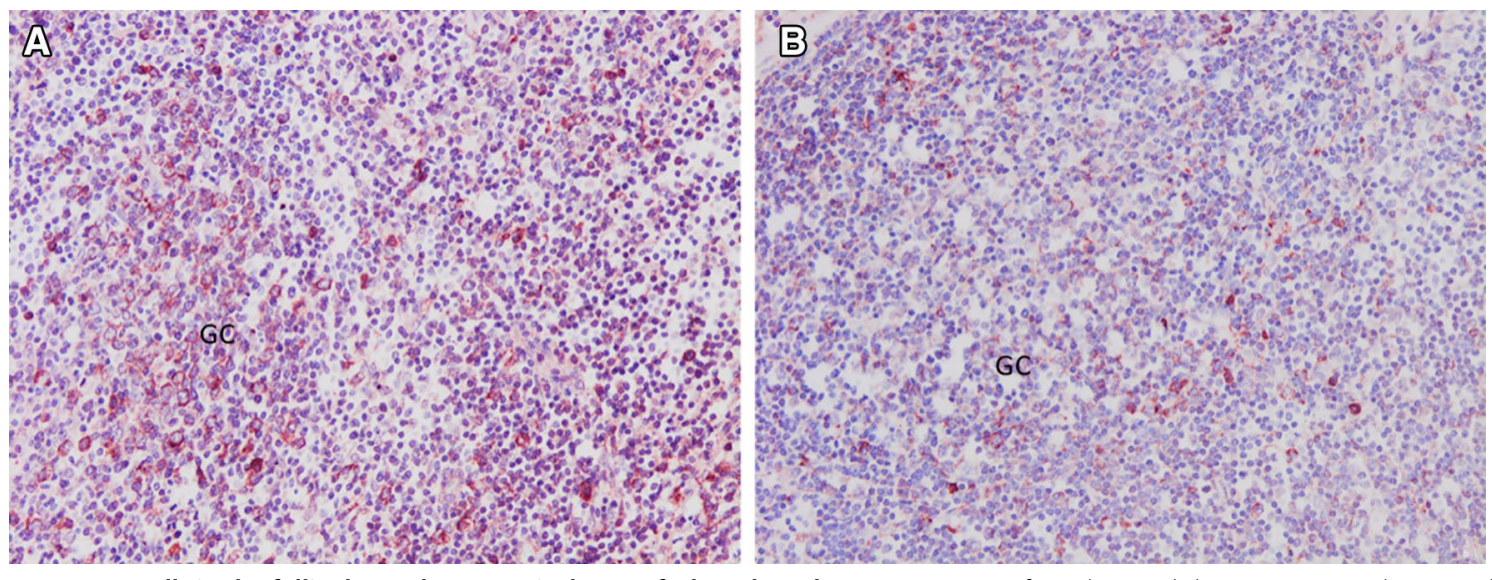

Figure 5 CD83+ cells in the follicular and paracortical area of a lymph node. A. From an uninfected control sheep. B. From a sheep 18 dpi. GC: germinal centre. ABC-haematoxylin counterstain, $\times 200$.

The CNA.42 antibody was expressed mainly by FDC located in the light zones of the germinal centres of lymphoid follicles, an expression pattern that was also reported for human [41] and sheep [13] lymph nodes using the same antibody. Sheep FDC have been identified as cells forming a reticular pattern in the light zone of the germinal centres and playing important roles in the selection of memory B lymphocytes during germinal centre reactions $[13,42]$.

The significant increase in the expression of the CNA.42 antibody at $18 \mathrm{dpi}$, compared to that in the UC group, coincided with marked hyperplasia of germinal centres at $18 \mathrm{dpi}$. This result agrees with the marked increased expression of the same antibody in human hyperplastic germinal centres reported in other conditions [41]. The increased expression of CNA.42 in the liver at 18 dpi may be related to the substantial increase in inflammatory infiltrate at $18 \mathrm{dpi}$ compared to that seen in the UC group, in which only occasional inflammatory cells were found in the portal spaces. The present study is the first to analyse the expression of CNA.42 in F. hepat$i c a$-infected ruminants, and there are a limited number of published studies describing the expression of FDC in other helminth infections. It has been reported that the enteric nematode Heligmosomoides polygyrus induces FDC overexpression in mouse mesenteric lymph nodes $[43,44]$. Similarly, subcutaneous reactive lymph nodes from human patients suffering onchocerciasis showed strong expression of FDC in germinal centres [45]. These results agree with the increased number of CNA.42+ cells in both the liver and HLNs of $F$. hepatica-infected sheep found at $18 \mathrm{dpi}$ in the present study.

Previous studies have reported the presence of a second population of FDC, localized to the dark zones of sheep germinal centres, but their function has yet to be defined [13, 46-48]. These cells did not express the classical FDC marker CNA.42 but stained positively for CD83 and S100, suggesting that the FDC in the dark zone are a less specialized subpopulation of reticular cells that might share a similar origin with the light zone FDC [13]. The number of S100+ stromal cells increased in HLN follicles and paracortical and medullary areas of animals at $18 \mathrm{dpi}$, compared with that seen in animals at $9 \mathrm{dpi}$. In the liver, the number of S100+ stromal cells increased significantly at $18 \mathrm{dpi}$ in comparison with that in the UC group.

Furthermore, the $\mathrm{S} 100$ protein is expressed by activated FDC, which may explain why anti-S100 gave rise to individual cell staining. Transcriptomic analysis of PBMCs from sheep revealed an upregulation of S100 genes at 2 weeks post-infection, and these cells were shown to be involved in leukocyte migration and the innate immune response [49]. In a murine model, the S100A8 gene was also overexpressed in $F$. hepatica infections [50].

The CD1b molecule is expressed by a mature population of migrating DC from sheep peripheral lymph nodes and induces the proliferative response of $\mathrm{CD} 4+\mathrm{T}$ cells and antigen presentation to promote pro-inflammatory (IL-6), pro-Th1 (IL-12p40) and anti-inflammatory (IL10) responses. These responses were amplified by Salmonella antigens and limited to only IL- 6 induction by helminth secretions [32, 51]. Leishmania spp. infection of human monocyte-derived dendritic cells resulted in reduced expression of CD1b [52]. Similar results were found in bovine monocyte-derived macrophages infected with Neospora caninum [53]. These results contrast with those found in the present study, in which the number of $\mathrm{CD} 1 \mathrm{~b}+\mathrm{DC}$ increased significantly in HLNs and livers at 18 dpi compared to that in the UC group. The difference in the expression of $\mathrm{CD} 1 \mathrm{~b}$ in the two parasites may be 
related to differences in the host response to N. caninum and $F$. hepatica infections in cattle and sheep, respectively. Thus, in N. caninum-infected cattle, elevated reactive oxygen species (ROS), IL-10 and IFN- $\gamma$ production has been reported [53], whereas in $F$. hepatica-infected sheep, decreased ROS production [54] and decreased IFN- $\gamma$ gene expression have been observed [15].

The results of the present study reveal a significant decrease in the cellular expression of the antigen presentation markers CD83 and MHC-II by DC and FDC in the lymph nodes of sheep experimentally infected with $F$. hepatica. CD83 is broadly used as a maturation marker for human and mouse DC $[55,56]$. Nevertheless, it is also expressed on a variety of different cells, including monocytes and macrophages [56] and activated $\mathrm{B}$ and $\mathrm{T}$ lymphocytes [57-59]. CD83 expression in sheep has been described in pseudo-afferent lymph DC [60]. The same monoclonal CD83 antibody used in the present work identified DC in the paracortical area of lymph nodes displaying a marked cytoplasmic localization, while it was not detected in macrophages located along the medullary sinuses, and it labelled B cells located in the lymphoid follicles that formed a fine reticulum-a staining pattern consistent with that expected for FDC [13]. In our study, the decreased expression of CD83 in DC and FDC of paracortical areas and germinal centres, respectively at 9 and $18 \mathrm{dpi}$ agrees with the decreased expression of the same cell marker in peritoneal leucocytes from $F$. hepatica-infected sheep at 3 and $9 \mathrm{dpi}$ [54] and with the decrease in the expression of CD83 in monocyte-derived DC cocultured in the presence Anisakis pegreffi live larvae and their crude extracts [61], as well as T. multiceps [62] and T. spiralis [63]. Since the expression of the CD83 molecule in mature DC could have a specialized function during antigenic presentation, contributing to lymphoid activation [64], reduced CD83 expression during $F$. hepatica infection in sheep suggests a modulatory effect that impairs antigenic presentation and, therefore, the host immune response during the early stages of infection. The lower level of CD83 expression in stellate cells of the dark zone of lymphoid follicles observed in the present study agrees with previous studies using the same antibody in sheep lymph nodes [13].

It has been reported that in fixed sheep lymph nodes, MHC-II is expressed at high levels by interdigitating cells present in the paracortex, at lower levels by the B lymphocytes present in the follicles, and at a lower level in macrophages from the medullary sinuses [13], an expression pattern also observed in our study. In the present study, the reduced MHC-II+ DC found in HLNs at 9 and $18 \mathrm{dpi}$, compared to the number in the UC group, agrees with the significant decrease in
MHC-II in the peritoneal leukocytes of sheep experimentally infected with $F$. hepatica at 9 dpi [54], with the reduced expression of MHC-II in DC from buffalos cultured in the presence of ESPs from F. gigantica [20], and with the low MHC-II expression in DC of mice cultured in the presence of mucin-like peptide $[30,65]$ or in the presence of FhTeg from F. hepatica [18].

In summary, an increase in CNA.42+ FDC and CD1b+ DC was found at $18 \mathrm{dpi}$ in HLNs compared with the respective numbers in the UC group, coinciding with marked hyperplasia of the germinal centres of HLNs. However, the expression of MHC-II and CD83 decreased at 9 and, particularly, at $18 \mathrm{dpi}$ in HLNs compared with that in the UC group, suggesting that $F$. hepatica infection induces suppression of markers related to antigenic presentation.

\section{Abbreviations \\ DC: dendritic cells; FDC: follicular dendritic cells; CD1b: cluster of differentia- tion 1b; MHC-II: Major histocompatibility complex-II; CD83: cluster of differen- tiation 83; HLNs: hepatic lymph nodes; UC: uninfected control; FhTeg: Fasciola hepatica tegumental antigen; ESPs: excretory secretory products; IL-10: interleukin 10; IL-4: interleukin 4; FhCL1: Fasciola hepatica cathepsin L1; FhGST: Fasciola hepatica glutathione transferase; Fhmuc: Fasciola hepatica mucin-like peptide; IFN- $\gamma$ : interferon gamma; FhCL3: Fasciola hepatica cathepsin L3; IL-13: interleukin 13; ELISA: Enzyme-linked immunosorbent assay; PBS: phosphate- buffered saline; PBMCs: peripheral blood mononuclear cells; IL-6: interleukin 6; IL-12p40: interleukin 12p40; ROS: reactive oxygen species.}

\section{Acknowledgements}

We thank Leticia Gonzalez and Alberto Alcántara for their technical assistance.

\section{Authors' contributions}

The experiment was conceived and designed by AMM and JP. The experiment was performed by MTRC, VMH, MJB, FJMM, LLP and LB. The laboratory work was carried out by MTRC and VMH. The data were analysed statistically by RZ. The paper was written and revised by MTRC, VMH, AMM and JP. All authors read and approved the final manuscript.

\section{Funding}

This work was supported by EU grants (FPVII-265862-PARAVAC,

H2020-635408-PARAGONE) and a national grant (AGL2015-67023-C2-1-R).

VMH is supported by the "Juan de la Cierva-Incorporacion" contract (IJCI-2017-

31366) of the Spanish Ministry of Science, Innovation and Universities.

\section{Availability of data and materials}

All data are available, upon reasonable request, from the corresponding author.

\section{Ethics approval}

The experiment was approved by the Bioethics Committee of the University of Cordoba (No. 1118) and conducted in accordance with European (2010/63/ UE) and Spanish (RD 1201/2005) directives on animal experimentation.

\section{Competing interests}

The authors declare that they have no competing interests.

\section{Author details}

${ }^{1}$ Department of Anatomy and Comparative Pathology, Faculty of Veterinary Medicine, University of Córdoba, Sanidad Animal Building, Rabanales Campus, Córdoba, Spain. ${ }^{2}$ Department of Animal Health (Parasitology), Faculty of Veterinary Medicine, University of Córdoba, Sanidad Animal Building, Rabanales Campus, Córdoba, Spain. 
Received: 30 September 2019 Accepted: 3 December 2019

Published online: 04 March 2020

\section{References}

1. Mehmood K, Zhang H, Sabir AJ, Abbas RZ, ljaz M, Durrani AZ, Saleem MH, Ur Rehman M, lqbal MK, Wang Y, Ahmad Hl, Abbas T, Hussain R, Ghori MT, Ali S, Khan AU, Li J (2017) A review on epidemiology, global prevalence and economical losses of fasciolosis in ruminants. Microb Pathog 109:253-262

2. Mas-Coma S (2005) Epidemiology of fasciolasis in human endemic areas. J Helminthol 79:207-216

3. González LC, Esteban JG, Bargues MD, Valero MA, Ortiz P, Náquira C, MásComa S (2011) Hyperendemic human fasciolasis in Andean valleys: an altitudinal transect analysis in children of Cajamarca province, Peru. Acta Trop 120:119-129

4. Fairweather I (2009) Triclabendazole progress report, 2005-2009: an advancement of learning? J Helminthol 83:139-150

5. Dalton JP, O'Neill S, Stack C, Collins P, Walshe A, Sekiya M, Doyle S, Mulcahy G, Hoyle D, Khazznadji E, Moire N, Brennan G, Mousley A, Kreshchenko N, Maule AG, Donnelly SM (2003) Fasciola hepatica cathepsin L-like proteases: biology, function and potential in the development of first generation liver fluke vaccines. Int J Parasitol 33:1173-1181

6. Piedrafita D, Spithill TW, Smith RE, Raadsma HW (2010) Improving animal and human health through understanding liver fluke immunology. Parasite Immunol 32:572-581

7. Dalton JP, Robinson MW, Mulcahy G, O'Neill SM, Donnelly S (2013) Immunomodulatory molecules of Fasciola hepatica: candidates for both vaccine and immunotherapeutic development. Vet Parasitol 195:272-285

8. Toet H, Piedrafita DM, Spithill TW (2014) Liver fluke vaccines in ruminants: strategies, progress and future opportunities. Int J Parasitol 44:915-927

9. Molina-Hernández V, Mulcahy G, Pérez J, Martínez-Moreno A, Donnelly S, O’Neill SM, Dalton JP, Cwiklinski K (2015) Fasciola hepatica vaccine: we may not be there yet but we're on the right road. Vet Parasitol 208:101-111

10. Dowling DJ, Hamilton CM, Donnelly S, La Course J, Brophy PM, Dalton J, O'Neill SM (2010) Major secretory antigens of the helminth Fasciola hepatica activate a suppressive dendritic cell phenotype that attenuates Th17 cells bus fails to activate Th2 immune responses. Infect Immun 78:793-801

11. Falcón C, Carranza F, Martínez FF, Knubel CP, Masih DT, Motrán CC, Cervi L (2010) Excretory-secretory products (ESP) from Fasciola hepatica induce tolerogenic properties in myeloid dendritic cells. Vet Immunol Immunopathol 137:36-46

12. Vukman KV, Adams PN, O'Neill SM (2013) Fasciola hepatica tegumental coat antigen suppresses MAPK signalling in dendritic cells and upregulates the expression of SOCS3. Parasite Immunol 35:234-238

13. Melzi E, Rocchi MS, Entrican G, Caporale M, Palmarini M (2018) Immunophenotyping of sheep paraffin-embedded peripheral lymph nodes. Front Immunol 9:2892

14. Kranich J, Krautler NJ (2016) How follicular dendritic cells shape the B-cell antigenome. Front Immunol 7:225

15. Pacheco IL, Abril N, Morales-Prieto N, Bautista MJ, Zafra R, Escamilla A, Ruiz MT, Martínez-Moreno A, Pérez J (2017) Th1/Th2 balance in the liver and hepatic lymph nodes of vaccinated and unvaccinated sheep during acute stages of infection with Fasciola hepatica. Vet Parasitol 238:61-65

16. Chung JY, Bae YA, Yun DH, Yand HJ, Kong Y (2012) Experimental murine fasciolasis derives early immune suppression with increased levels of TGFb and IL-4. Korean J Parasitol 50:301-308

17. Ingale SL, Singh P, Raina OK, Mehra UR, Verma AK, Gupta SC, Mulik SV (2008) Interferon-gamma and interleukin-4 expression during Fasciola gigantica primary infection in crossbred bovine calves as determined by real-time PCR. Vet Parasitol 152:158-161

18. Hamilton CM, Dowling DJ, Loscher CE, Morphew RM, Brophy PM, O'Neill SM (2009) The Fasciola hepatica tegumental antigen suppresses dendritic cell maturation and function. Infect Immun 77:2488-2498

19. Falcón CR, Carranza FA, Aoki P, Motrán CC, Cervi L (2012) Adoptive transfer of dendritic cells pulsed with Fasciola hepatica antigens and lipopolysaccharides confers protection against fasciolosis in mice. J Infect Dis 205:506-514
20. Mei XF, Shi W, Zhang YY, Zhu B, Wang YR, Hou LJ, Zhao WP, Li J, Wang DY, Luo HL, Huang WY (2019) DNA methylation and hydroxymethylation profiles reveal possible role of highly methylated TLR signaling on Fasciola gigantica excretory/secretory products (FgESPs) modulation of buffalo dendritic cells. Parasit Vectors 12:358

21. Aldridge A, O'Neill SM (2016) Fasciola hepatica tegumental antigens induce anergic-like T cells via dendritic cells in a mannose receptordependent manner. Eus J Immunol 46:1180-1192

22. O'Neill S, Brady MT, Callanan JJ, Mulcahy G, Joyce P, Mills KH, Dalton JP (2000) Fasciola hepatica infection downregulates Th1 responses in mice. Parasite Immunol 22:147-155

23. Flynn RJ, Mulcahy G (2008) The roles of IL-10 and TGF-beta in controlling $\mathrm{IL}-4$ and IFN-gamma production during experimental Fasciola hepatica infection. Int J Parasitol 38:1673-1680

24. Walsh KP, Brady MT, Finlay CM, Boon L, Mills KH (2009) Infection with a helminth parasite attenuates autoimmunity trough TGF-beta-mediated suppression of Th17 and Th1 responses. J Immunol 183:1577-1586

25. Rodríguez E, Kalay H, Noya V, Brossard N, Giacomini C, van Kooyk Y, García-Vallejo JJ, Freire T (2017) Fasciola hepatica glycoconjugates immuneregulate dendritic cells through the Dendritic Cell-Specific Intercellular adhesion molecule-3-Grabbing Non-integrin inducing T cell anergy. Sci Rep 7:46748

26. Donnelly S, O'Neill SM, Sekiya M, Mulcahy G, Dalton JP (2005) Thioredoxin peroxidase secreted by Fasciola hepatica induces the alternative activation of macrophages. Infect Immun 73:166-173

27. Guasconi L, Serradell MC, Garro AP, lacobelli L, Masih DT (2011) C-type lectins on macrophages participate in the immunomodulatory response to Fasciola hepatica products. Immunology 133:386-396

28. Adams PN, Aldridge A, Vukman KV, Donnelly S, O’Neill SM (2014) Fasciola hepatica tegumental antigens indirectly induce an M2 macrophage-like phenotype in vivo. Parasite Immunol 36:531-539

29. Falcón CR, Masih D, Gatti G, Sanchez MC, Motrán CC, Cervi L (2014) Fasciola hepatica Kunitz type molecule decreases dendritic cell activation and their ability to induce inflammatory responses. PLoS ONE 9:e114505

30. Noya V, Brossard N, Rodríguez E, Dergan-Dylon LS, Carmona C, Rabinovich GA (2017) Freire T (2017) A mucin-like peptide from Fasciola hepatica instructs dendritic cells with parasite specific Th1-polarizing activity. Sci Rep 7:40615

31. Celias DP, Corvo I, Silvane L, Tort JF, Chiapello LS, Fresno M, Arranz A, Motrán CC, Cervi L (2019) Cathepsin L3 from Fasciola hepatica induces NLRP3 inflammasome alternative activation in murine dendritic cells. Front Immunol 10:552

32. Olivier M, Foret B, Le Vern Y, Guilloteau LA (2012) Capacities of migrating CD1b+ lymph dendritic cells to present Salmonella antigens to naive T cells. PLOS ONE 7:e30430

33. Escamilla A, Zafra R, Pérez J, McNeilly TN, Pacheco IL, Buffoni L, MartínezMoreno FJ, Molina-Hernández V, Martínez-Moreno A (2016) Distribution of Foxp3+T cells in the liver and hepatic lymph nodes of goats and sheep experimentally infected with Fasciola hepatica. Vet Parasitol 230:14-19

34. Meeusen E, Lee CS, Rickard MD, Brandon MT (1995) Cellular responses during liver fluke infection in sheep and its evasion by the parasite. Parasite Immunol 17:37-45

35. Escamilla A, Bautista MJ, Zafra R, Pacheco IL, Ruiz MT, Martínez-Cruz S, Méndez A, Martínez-Moreno A, Molina-Hernández V, Pérez J (2016) Fasciola hepatica induces eosinophil apoptosis in the migratory and biliary stages of infection in sheep. Vet Parasitol 216:84-88

36. Zafra R, Pérez-Écija RA, Buffoni L, Moreno P, Bautista MJ, Martínez-Moreno A, Mulcahy G, Dalton JP, Pérez J (2013) Early and late peritoneal and hepatic changes in goats immunized with recombinant cathepsin L1 and infected with Fasciola hepatica. J Comp Pathol 148:373-384

37. Zafra R, Pérez-Écija RA, Buffoni L, Pacheco IL, Martínez-Moreno A LaCourse EJ, Perally S, Brophy PM, Pérez J (2013) Early hepatic and peritoneal changes and immune response in goats vaccinated with a recombinant glutathione transferase sigma class and challenged with Fasciola hepatica. Res Vet Sci 94:602-609

38. Chauvin A, Bouvet G, Boulard C (1995) Humoral and cellular immune responses to Fasciola hepatica experimental primary and secondary infection in sheep. Int J Parasitol 25:1227-12241

39. Chauvin A, Moreau E, Boulard C (2001) Responses of Fasciola hepatica infected sheep to various infection levels. Vet Res 32:87-92 
40. Pérez J, Ortega J, Moreno T, Morrondo P, López-Sánchez C, MartínezMoreno A (2002) Pathological and immunohistochemical study of the liver and hepatic lymph nodes of sheep chronically reinfected with Fasciola hepatica, with or without triclabendazole treatment. J Comp Pathol 127:30-36

41. Kasajima-Akatsuka N, Maeda K (2006) Development, maturation and subsequent activation of follicular dendritic cells (FDC): immunohistochemical observation of human fetal and adult lymph nodes. Histochem Cell Biol 126:261-273

42. Johnson LA, Clasper S, Holt AP, Lalor PF, Baban D, Jackson DG (2006) An inflammation-induced mechanism for leukocyte transmigration across lymphatic vessel endothelium. J Exp Med 203:2763-2777

43. King IL, Mohrs M (2009) IL-4-producing CD4+ T cells in reactive lymph nodes during helminth infection are T follicular helper cells. J Exp Med 206:1001-1007

44. Zaretsky A, Taylor JJ, King IL, Marshal FA, Mohrs M, Pearce EJ (2009) T follicular helper cells differentiate from Th2 cells in response to helminth antigens. J Exp Med 206:991-999

45. Brattig NW, Tenner-Racz K, Korten S, Hoerauf A, Büttner DW (2010) Immunohistology of ectopic secondary lymph follicles in subcutaneous nodules from patients with hyperreactive onchocerciasis (sowda). Parasitol Res 107:657-666

46. Yoshida K, van den Berg TK, Dijkstra CD (1993) Two functionally different follicular dendritic cells in secondary lymphoid follicles of mouse spleen, as revealed by CR1/2 and FcR gamma II-mediated immune-complex trapping. Immunology 80:34-39

47. Lefevre EA, Hein WR, Stamataki Z, Brackenbury LS, Supple EA, Hunt LG, Monaghan P, Borhis G, Richard Y, Charleston B (2007) Fibrinogen is localized on dark zone follicular dendritic cells in vivo and enhances the proliferation and survival of a centroblastic cell line in vitro. J Leukoc Biol 82:666-677

48. Allen CDC, Cyster JG (2008) Follicular dendritic cell networks of primary follicles and germinal centers: phenotype and function. Semin Immuno 20:14-25

49. Álvarez-Rojas CA, Scheerlinck JP, Ansell BR, Hall RS, Gasser RB, Jex AR (2016) Time-course study of the transcriptome of peripheral blood mononculear cells (PBMCs) from sheep infected with Fasciola hepatica. PLoS ONE 11:e0159194

50. Rojas-Caraballo J, López-Abán J, Moreno-Pérez DA, Vicente B, FernándezSoto P, Del Olmo E, Patarroyo MA, Muro A (2017) Transcriptome profiling of gene expression during immunisation trial against Fasciola hepatica: identification of genes and pathways involved in conferring immunoprotection in a murine model. BMC Infect Dis 17:94

51. Olivier M, Foret B, Le Vern Y, Kerboeuf D, Guilloteau LA (2013) Plasticity of migrating CD1b+ and CD1b- lymph dendritic cells in the promotion of Th1, Th2 and Th17 in response to Salmonella and helminth secretions. PLoS ONE 8:e79537

52. Donovan MJ, Jayakumar A, McDowell MA (2007) Inhibition of groups 1 and 2 CD1 molecules on human dendritic cells by Leishmania species. Parasite Immunol 29:515-524

53. García-Sánchez M, Jiménez-Pelayo L, Horcajo P, Regidor-Cerrillo J, Ólafsson EB, Bhandage AK, Barragan A, Werling D, Ortega-Mora LM, CollantesFernández E (2019) Differential responses of bovine monocyte-derived macrophages to infection by Neospora caninum isolates of high and low virulence. Front Immunol 10:915
54. Pérez-Caballero R, Martínez-Moreno FJ, Zafra R, Molina-Hernández V, Pacheco IL, Ruiz-Campillo MT, Escamilla A, Pérez J, Martínez Moreno A, Buffoni $L$ (2018) Comparative dynamics of peritoneal cell immunophenotypes in sheep during the early and late stages of the infection with Fasciola hepatica by flow cytometric analysis. Parasit Vectors 11:640

55. Breloer M (2008) CD83: regulator of central T cell maturation and peripheral immune response. Immunol Lett 115:16-17

56. Cao W, Lee SH, Lu J (2005) CD83 is preformed inside monocytes, macrophages and dendritic cells, but it is only stably expressed on activated dendritic cells. Biochem J 385:85-93

57. Wolenski M, Cramer SO, Ehrlich S, Steeg C, Großschupff G, Tenner-Racz K, Racz P, Fleischer B, von Bonin A (2003) Expression of CD83 in the murine immune system. Med Microbiol Immunol 192:189-192

58. Victoria GD, Dominguez-Sola D, Holmes AB, Deroubaix S, Dalla-Favera R, Nussenzweig MC (2012) Identification of human germinal center light and dark zone cells and their relationship to human B-cell lymphomas. Blood 120:2240-2248

59. Krzyzak L, Seitz C, Urbat A, Hutzler S, Ostalecki C, Gläsner J, Hiergeist A, Gessner A, Winkler TH, Steinkasserer A, Nitschke L (2016) CD83 modulates $B$ cell activation and gernimal center responses. J Immunol 196:3581-3594

60. Newland A, Kireta S, Russ G, Krishnan R (2004) Ovine dendritic cells transduced with an adenoviral CTLA4eEGFP fusion protein construct induce hyporesponsiveness to allostimulation. Immunology 113:310-317

61. Napoletano C, Mattiucci S, Colantoni A, Battisti F, Zizzari IG, Rahmi H, Nuti M, Rughetti A (2018) Anisakis pegreffii impacts differentiation and function of human dendritic cells. Parasite Immunol 40:e12527

62. Terrazas LI, Walsh KL, Piskorska D, McGuire E, Harn DA Jr (2001) The schistosome oligosaccharide lacto-N-neotetraose expands Gr1(+) cells that secrete anti-inflammatory cytokines and inhibit proliferation of naïve CD4(+) cells: a potential mechanism for immune polarization in helminth infections. J Immunol 167:5294-52303

63. Aranzamendi C, Fransen F, Langelaar M, Franssen F, van der Ley P, van Putten JP, Rutten V, Pinelli E (2012) Trichinella spiralis-secreted products modulate DC functionality and expand regulatory $T$ cells in vitro. Parasite Immunol 34:210-223

64. Scholler N, Hayden-Ledbetter M, Hellström KE, Hellström I, Ledbetter JA (2001) CD83 is an l-type lectin adhesion receptor that binds monocytes and a subset of activated CD8+T cells. J Immunol 166:3865-3872

65. Rodríguez E, Noya V, Cervi L, Chiribao ML, Brossard N, Chiale C, Carmona C, Giacomini C, Freire T (2015) Glycans from Fasciola hepatica modulate the host immune response and TLR-induced maturation of dendritic cells. PLoS Negl Trop Dis 9:e0004234

66. Mozos E, Méndez A, Martín MP, Herráez P, Pérez J (1998) Ovine cutaneous squamous cell carcinoma: immunohistochemical expression of CD3, CD4, CD8 and MHC class II antigens in the associated inflammatory infiltrate. Vet Immunol Immunopathol 61:221-228

\section{Publisher's Note}

Springer Nature remains neutral with regard to jurisdictional claims in published maps and institutional affiliations.

Ready to submit your research? Choose BMC and benefit from

- fast, convenient online submission

- thorough peer review by experienced researchers in your field

- rapid publication on acceptance

- support for research data, including large and complex data types

- gold Open Access which fosters wider collaboration and increased citations

- maximum visibility for your research: over 100M website views per year

At BMC, research is always in progress.

Learn more biomedcentral.com/submissions 